\title{
FITOGEOGRAFÍA DE LA MANCOMUNIDAD DE ALMOGUERA (GUADALAJARA) (II). ESTUDIO ESPECIAL DE LAS FORMACIONES DE MATORRALES GIPSÍCOLAS
}

\author{
POR \\ JUAN JAVIER GARCÍA-ABAD ALONSO
}

\section{Introducción}

En un trabajo anterior se trataron ya aspectos generales de la investigación fitogeográfica que aquí continúa: caracterización geográfica de la Mancomunidad de Almoguera, factores fundamentales que han intervenido en la configuración del paisaje vegetal actual, técnicas y enfoque metodológico empleados, y presentación de las formaciones climatófilas arbóreo-arborescentes y matorrales no gipsícolas (GarcíaAbad, 1998 ó Parte I). El presente artículo constituye, pues, una segunda parte en donde se prosigue el análisis fitogeográfico de las formaciones climatófilas (o de interfluvio), dedicado a los matorrales gipsícolas que se hayan extensamente representados en el área de estudio y que suponen una respuesta de la vegetación a las especiales condiciones litológicas del medio (presencia de yesos y margas yesíferas), tal y como se expuso en el trabajo precedente y al cual nos remitimos para una adecuada comprensión.

Los matorrales gipsícolas, en este territorio del límite meridional de las provincias de Guadalajara y Madrid, representan estadios casi extremos o extremos, bien de condiciones fitocenóticas naturales poco generosas, bien de degradación del medio natural. Este significado geoecológico particular ha motivado su estudio especial.

Juan Javier García-Abad Alonso. Dpto. de Geografía. Universidad de Alcalá de Henares.

Estudios Geográficos, LXII, 244, 2001

$$
-413-
$$


Con objeto de observar mejor la viariabilidad fitogeográfica de los matorrales gipsícolas, en este trabajo se han incluido también algunos inventarios florísticos y análisis de suelos de localizaciones externas a la Mancomunidad, pero relativamente próximas: municipios de Valdeconcha y Pastrana, por el norte, y Albalate de Zorita e Illana (incluida la jurisdicción de Aldovera, perteneciente a ambos), por el este.

\section{Fitogeografía de los matorrales gipsícolas}

La exposición de las formaciones vegetales seguirá un orden creciente hacia la pobreza o degradación del medio y, a veces, en paralelo a una artificialización progresiva del mismo. En este espacio alcarreño, dicho fenómeno suele corresponder, normalmente, a diferentes grados de intervención antropozoógena, que desembocan en una disminución paulatina de la biomasa y en una decantación eutrofa de la vegetación. El recorrido evolutivo de la misma, en definitiva, va marcando una serie de peldaños o fases de distinto significado geoecológico, interesantes para la interpretación y evaluación ambientales.

La presencia actual de estos matorrales responde, como los otros de este territorio, a etapas seriales del quejigar (Quercus faginea subesp. faginea) y, sobre todo, del encinar ( $Q$. ilex subsp. ballota) y del coscojar (Q. coccifera). Su peculiaridad es una particular apetencia edáfica, que confiere a este ámbito comarcal una relativa autonomía fitogeográfica (probablemente, a nivel de distrito, según el sistema biogeográfico de Géhu y Rivas-Martínez, 1981) y, sin duda, una singularidad florística culminada por algunos endemismos a nivel de provincia biogeográfica (Peinado y Martínez-Parras, 1985).

Los matorrales gipsófilos o gipsícolas están constituidos por arbustos y algunas herbáceas especialmente adaptadas a los suelos yesíferos y que no prosperan fuera de ellos (estonoicos), pues incluyen plantas que sólo se encuentran en ese tipo de medios (gipsófitos exclusivos, según Rivas-Martínez y Costa, 1970). Cuando esta dependencia se atempera o atenúa, pero siguen ocupando frecuentemente estos sustratos, las plantas pueden considerarse subgipsófitos.

No deben confundirse estas formaciones con otras de significado fitoecológico y fitosociológico emparentado o relacionado, y que se encuentran o pueden encontrarse geográfica y localmente próximas. En pri-

Estudios Geográficos, LXII, 244, 2001

$$
-414-
$$


mer lugar, no deben confundirse con formaciones no estrictamente gipsófilas, integradas por gipsófitos facultativos; es decir, plantas vasculares que, presentándose en suelos yesíferos, tienen una mayor amplitud ecológica, pudiendo también prosperar en otro tipo de suelos (Rivas-Martínez y Costa, 1970), donde es normal que presenten su desarrollo óptimo y distribución geográfica principal. Se trata de agrupaciones vegetales que toleran niveles variables de yeso en el suelo y que, por tanto, acompañan a las estrictamente gipsícolas, formando con ellas yuxtaposiciones, mezclas y asociaciones (sentido no fitosociológico).

Por ello, junto a esas formaciones gipsófilas exclusivas, se pueden encontrar ocupando terrenos moderada a ligeramente yesíferos otras formaciones con cierto grado de afinidad florística, fitoecológica o, cuando menos, geográfica: espartales (Stipa tenacissima), tomillares no exclusivos de yesos (Thymus vulgaris, T. zygis), retamares (Retama sphaerocarpa), aliagares (Genista scorpius), esplegares (Lavandula latifolia), salviares (Salvia lavandulifolia), romerales (Rosmarinus officinalis, Cistus clusii), coscojares (Quercus coccifera), incluso encinares y algunas comunidades edafohigrófilas, además de otros matorrales y de herbazales no estrictamente gipsófilos. En estos casos es común encontrar localidades y biotopos ecotónicos, sobre todo en áreas que, como el de la Mancomunidad de Almoguera, posee otros tipos de litologías alternando con los yesos.

En segundo lugar, no deben confundirse tampoco con formaciones estrictamente salinas o halófilas, calificativo que se aplica a las plantas que crecen sólo en los medios salinos, entendiendo que las sales implicadas en ellos son otras más solubles que el yeso: cloruro sódico, magnésico, sulfato sódico...

Las especies gipsícolas genuinas son de pequeña talla, nunca llegan a ser árboles o arbustos grandes, limitándose a plantas fruticosas y sufruticosas de porte subarbustivo y herbáceo, y a herbáceas también de reducido tamaño. Son algo carnosas o crasas, en ocasiones, así como postradas o decumbentes. En cuanto a las formas vitales, dominan los caméfitos, normalmente enanos, y nanoterófitos, habiendo también algunos hemicriptófitos y muy escasos nanofanerófitos. En el área, florísticamente dominan las cariofiláceas, seguidas de compuestas, gramíneas, cistáceas y labiadas.

Las formaciones que resultan, denominadas aljezares o yesares, son bastante abiertas, ya que poseen una baja cobertura del suelo du-

Estudios Geográficos, LXII, 244, 2001 
rante la mayor parte del año, dando sus matas dispersas un aspecto moteado característico sobre el fondo blanquecino y grisáceo a versicolor claros del suelo yesífero y margo-yesífero. Es caracaterística, también, en ellas la frecuente presencia de una capa o costra de líquenes en esos espacios desnudos o claros, bajo el dosel vascular. Estos líquenes actúan como comunidades pioneras, iniciando los primeros procesos edafogenéticos allí donde el yeso-roca es todavía masivo, puro o poco alterado (Costa Talens, 1974); facilitando la posterior implantación de plantas vasculares en estos medios.

a) Suelos yesíferos y régimen hidroclimático-. En este territorio, los suelos se convierten en un factor fitogeográfico determinante. En la ecología vegetal, los suelos salinos y yesíferos afectan al desarrollo de las plantas, por el incremento de la presión osmótica que producen en la solución del suelo (Hernando et al., 1963). Ello obliga a que las plantas deban aumentar, igualmente, la concentración salina de sus células con objeto de permitir el paso del agua a su interior y, con ella, de los elementos necesarios para su nutrición. De esta manera, la concentración excesiva de sulfatos y de otras sales más solubles sería tóxica para la mayor parte de las plantas.

Los suelos yesíferos principales que pueden encontrarse en este área, según la clasificación FAO (Jimeno y González, 1987; Monturiol y Alcalá del Olmo, 1989; García-Abad, 1996a), son los gypsisoles, sobre todo cálcicos y háplicos; regosoles gypsicos y leptosoles líticos. En cuanto a los suelos no yesíferos, próximos a ellos se encuentran otros regosoles y leptosoles, anthrosoles y algunos cambisoles.

Aquéllos presentan habitualmente epipediones ócricos y es normal, también, encontrar endopediones gypsicos e hipergypsicos (según nomenclatura de Porta et al., 1994). En campo, se observa claramente cómo la evolución edafogenética progresiva se va correspondiendo con una producción de biomasa y cubrimiento del suelo mayores por parte de las plantas. Esta gradación responde a secuencias edafogenéticas propiciadas por controles litológico y topográfico (Birkeland, 1984), que comienzan en ecotonos por contacto de yesos con calizas, margas o materiales detríticos; sigue por suelos yesíferos bien desarrollados en profundidad y con cierto acúmulo de materia orgánica; pasa por suelos yesíferos enriquecidos en nitrógeno y sales; hasta llegar a los suelos yesíferos que pueden considerarse normales (yesosos, en ter-

Estudios Geográficos, LXII, 244, 2001

$$
-416-
$$


minología de Porta et al., 1994) y, finalmente, a lo que podríamos denominar protosuelos yesíferos, caracterizados por una incipiente alteración del yeso-roca y un paupérrimo o casi inexistente contenido en materia orgánica. En la Figura 1 se ilustra un caso de secuencia edafotopográfica en yesos, con tres perfiles de diferente desarrollo edafogenético, que dan cabida a formaciones vegetales de diferente significado dinámico, fitoecológico y florístico (los datos corresponden a los mismos parámetros del Cuadro III).

En las últimas secuencias referidas, el condicionante edáfico llega a ser tan limitante que da pie a recapacitar sobre la pertinencia, en algunas localizaciones, de considerar a estas formaciones como vegetación permanente antes que como vegetación climatófila, debido a las escasas posibilidades de sucesión a series progresivas.

$\mathrm{Al}$ factor edáfico, se une otro climático en la implantación de las formaciones gipsícolas exclusivas. En el sector yesífero de la Mancomunidad de Almoguera, las precipitaciones son escasas: entre 400 y $475 \mathrm{~mm}$ (García-Abad, 1996b). Esto dificulta el lavado y dispersión de esos elementos solubles, permaneciendo así mayores concentraciones y durante mayor tiempo en el suelo. Igualmente, las temperaturas elevadas y la sequía estival, producen una fuerte evapotranspiración -ETP media anual entre 725 y $775 \mathrm{~mm}$ - (García-Abad, 1996b), que favorece la persistencia de esos elementos en los niveles subsuperficiales y superficiales del suelo, por el movimiento ascendente del agua, dejándolos al alcance del aparato radicular de las plantas. Se comprueba, por tanto, que estas formaciones pierden su carácter paulatinamente, conforme el clima se vuelve menos caluroso y más húmedo (Rivas-Martínez y Costa, 1970); de lo que se deriva su naturaleza claramente xerofítica.

En suma, la conjunción de estas condiciones geográficas son selectivas y, en buena medida, excluyentes, dotando a las formaciones gipsícolas de una singularidad paisajística, contemplada por normas comunitarias (Directiva 92/43/CEE) en orden a conservar la biodiversidad. Las áreas que albergan estas formaciones se consideran zonas especiales de conservación (Red Natura 2000), en calidad de hábitats prioritarios (Rivas-Martínez et al., 1993).

b) Matorrales gipsícolas arbustivos- (Cuadro I). Son raras las formaciones gipsícolas que alcanzan este elevado porte. Sólo lo alcanzan algunos individuos de chucarro, zucarro o asnallo (Ononis tridentata), siendo el gipsófito exclusivo de mayor talla en el área de estudio. Lo ha- 
bitual es que esos pocos arbustales consistan en matorrales situados en localidades ecotónicas por contacto de sustratos calizos, margosos y otros asociados a ellos con sustratos yesíferos. Estos medios de transición edafo-litológica se localizan en zonas límite entre las unidades geológicas de las calizas del páramo (UTS-Sup) y las facies evaporíticas de la unidad intermedia (UTS-2), así como entre las distintas facies de ésta y de la unidad salina inferior ó UTS-1 (Garrido et al., 1983).

Los inventarios 1 y 5 del Cuadro I muestran dos casos de romeralchucarral que corresponden a localidades vecinas a la Mancomunidad de Almoguera. El primer ejemplo es en yesos garumnienses (Cretácico Superior) mezclados con materiales detríticos asociados a calizas. Se trata de los únicos afloramientos yesíferos del área no miocenos, de muy reducida extensión y aislados de los miocenos. En este pequeño sector, con precipitaciones superiores a los $525 \mathrm{~mm}$ (García-Abad, 1996b) y altitud relativamente elevada, las formaciones gipsícolas comienzan a perder su carácter genuino y exclusivo. En el segundo ejemplo (inv. 5) destaca la escasa presencia de gipsófitos exclusivos, en favor de subgipsófitos, así como diversos elementos del romeral, tomillar y salviar.

c) Matorrales gipsícolas bajos-. La mayor parte de formaciones gipsícolas corresponden a formaciones de porte muy bajo, pues salvo chucarrales y algunos jabunales, el resto no superan el estrato herbáceo. Se han reconocido los siguientes tipos y subtipos:

- Matorrales ecotónicos carbonático-yesíferos (Cuadro I).

Suponen, como en los casos anteriores, formaciones gipsícolas mezcladas florísticamente con otras que soportan menos los sustratos evaporíticos. Estos medios ecotónicos son puestos de manifiesto también por la aparición de algunas subasociaciones fitosociológicas (inventarios 2 y 6). Formaciones habituales son las de chucarrales con tomillares comunes (inv. 6) y con salviares (inv. 7) y de tomillares gipsícolas con romerales (invs. 2 y 3 ), con tomillares comunes (inv. 4), salviares (inv. 8) y otros (inv. 9).

- Matorrales gipsícolas.

Estas formaciones fruticosas tienen en el área de estudio bastante uniformidad florística (subalianza fitosociológica Lepidienion subulati Rivas-Martínez et al. 1993). Están constituidas mayoritariamente por gipsófitos exclusivos, sobre todo leñosos, además de algunas herbáceas y, secundariamente, por subgipsófitos y pequeños terófitos relativamente 
indiferentes al sustrato cuando el yeso-roca está ya alterado, hay un manto edáfico ligeramente desarrollado y cierto contenido en materia orgánica. Pero, con frecuencia aparecen enriquecidos con elementos florísticos de localidades fitocenóticas vecinas de medios no yesíferos, eutrofizados o ligeramente salinos.

En el territorio analizado, los gipsófitos genuinos que componen estas formaciones por orden de mayor a menor talla son los siguientes:

- Arbustos fruticosos: Chucarro, jabunas, jabunos o jaboneras (Gypsophila struthium, G. bermejoi), lepidio (Lepidium subulatum), jarilla o tomillo de escamas (Helianthemum squamatum), heliantemo conquense ( $H$. marifolium subesp. conquense), tomillo de Aranjuez (Thymus lacaitae) y Arenaria cavanillesiana.

- Arbustos frutiscentes: Albata o albaque (Centaurea hyssopifolia), Launaea resedifolia, herniaria (Herniaria fruticosa), Launaea pumila y Teucrium pumilum.

- Herbáceas: Koeleria castellana, Sedum gypsicola y Ctenopsis gypsophila.

Los subgipsófitos, con una amplitud ecológica algo mayor, aparecen también con mucha frecuencia: el romerillo (Helianthemum syriacum subesp. thibaudii) es un arbusto de talla mediana bastante termófilo, el Astragalus incanus es un pequeño arbusto decumbente y oportunista, como la herbácea Brassica repanda; el alhelí silvestre (Matthiola fruticulosa) es un subfrútice débilmente ruderal, al igual que la herbácea Reseda stricta; mientras que la oruga (Eruca vesicaria), algo más nitrófila, es una herbácea arvense.

La variabilidad de estos matorrales se aprecia en el dominio de alguno de sus componentes leñosos característicos y séquito acompañante en cada caso. Las distintas formaciones responden, esencialmente, al grado de alteración del yeso, a la evolución del suelo y a la cantidad de materia orgánica. Subtipos:

- Jabunales (Cuadro II).

Se caracterizan por el dominio claro de uno de los dos jabunos, pues no suelen encontrarse juntos, salvo excepciones (inv. 12); los demás componentes son los propios del tomillar gipsícola (invs. 11 y 12). Dan tonos cenicientos al paisaje. Ocupan el estrato herbáceo y, oca-

Estudios Geográficos, LXII, 244, 2001

$$
-419-
$$


sionalmente, el subarbustivo. La cobertura del suelo habitual oscila entre el 50 y el $65 \%$.

Precisan de yesos ya alterados, en suelos con horizonte superficial bien diferenciado. Aportan ya bastante materia orgánica al suelo. Tienen un carácter térmico y xerófilo (Izco, 1972 y 1984; Costa, 1974). Indican un grado evidente de recuperación del medio, suficiente para evolucionar progresivamente si las condiciones son favorables, como en antiguos campos abandonados (inv. 10). Son capaces de sostener bastante la erosión. Presentan variantes florísticas con cierta nitrofilia (inv. 12).

Se han analizado parcialmente dos perfiles de suelo en estas formaciones, hallándose una sobre sobre un gypsisol háplico (inv. 10; Cuadro III) y otra sobre un leptosol lítico (inv. 11; Figura 1b). En ambos casos, el epipedión es ócrico, existe endopedión hipergypsico (transitorio en el leptosol), los $\mathrm{pH}$ son ligeramente básicos, con niveles de salinidad destacables y muy alto contenido en yeso, sobre todo en el gypsisol, cuyo horizonte superficial recibe carbonatos procedentes de tramos próximos de ladera con calizas del páramo superior.

- Chucarrales (Cuadro II).

Domina el chucarro. Ocupan comúnmente el estrato subarbustivo y, cuando el medio es menos favorable, el herbáceo. La composición florística es bastante similar a la del jabunal, con la particularidad de que casi siempre va acompañado del tomillo de Aranjuez. Tiene un grado de cobertura del suelo algo mayor que el jabunal (60-75 \%). Se instala en suelos yesíferos que van perdiendo su carácter, por ser más profundos y algo menos secos o más frescos; así, el efecto de los sulfatos se modera relativamente, al estar los yesos más alterados, mezclados con materiales detríticos y margosos de facies contiguas, con mayor contenido en materia orgánica (invs. 13 y 14). En ellos puede aparecer un horizonte B (cambisoles). Esta formación tiene, por tanto, cierto carácter subyesífero de transición, por lo que es común observar en ellas especies no gipsícolas, gipsófitos facultativos o mezcladas con otras formaciones (como se observó en los inventarios 1, 5, 6 y 7). IV).

- Matorrales gipsícolas enriquecidos con ontinar y juncial (Cuadro

Cuando los suelos yesíferos, sobre todo en posiciones topográficas deprimidas, se enriquecen en nitrógeno por eutrofización antro-

Estudios Geográficos, LXII, 244, 2001

$$
-420-
$$


pozoógena, o bien presentan acumulación de otras sales por aportes exógenos o por presencia en el propio sustrato, la composición florística cambia parcial o substancialmente. Aparecen otras formaciones de carácter halonitrófilo o halófilo.

$\mathrm{El}$ inventario 15 es un ejemplo de comunidad nitrófila presidida por la ontina (Artemisia herba-alba), dominante sobre un muy reducido número de tomillos gipsícolas, en donde aparece también la herbácea halófita Lepidium cardamines. Se trata de una antigua tierra de cultivo situada en la parte baja de un pequeño vallezuelo entre dos antecerros yesíferos, que sufre actualmente una actividad ganadera extensiva. El suelo es un regosol gypsico formado sobre material detrítico arrastrado lateral y longitudinalmente hacia el talweg, recubriendo superficialmente el sustrato yesífero (Figura 1).

Por su parte, los invs. 16 y 18 muestran el caso de una comunidad subhalonitrófila mezclada con el jabunal. La juncia morisca, bastarda o negra (schoenus nigricans), junto a la zaragatona falsa (Plantago maritima) y la gramínea Elymus curvifolius forman una pradera salina, muy común en las lagunas arreicas manchegas (Peinado y Martínez-Parras, 1985), que indican la posible presencia de cloruros. Junto a ellas, las arvenses Lactuca serriola, cerraja (Sonchus asper) y barba cabruna (Tragopogon porrifolius); además de la oruga, la Reseda stricta, la hierba canina (Plantago albicans), el egílope rompesacos (Aegilops triuncialis), la avena loca (Avena sterilis), el farolitos (Stella scabiosa) y el Bromus tectorum indican distintos grados de nitrofilia en el medio. Estas localidades se sitúan en la parte baja de un cerro testigo calizo-yesífero (inv. 18) y en un reguero de arroyada próximo (inv. 16), proclives ambas al acúmulo de sales e hidromorfía temporal.

$\mathrm{El}$ inventario 17, en un diminuto cono de acumulación de detritus yesíferos por esporádicos arrastres hídricos, también presenta un fragmento del juncial morisco; en este caso, mezclado con tomillar gipsícola y especies ruderal-gipsícolas (alhelí silvestre y Reseda stricta), sobre formación superficial limo-arenosa recientemente sedimentada.

- Tomillares gipsícolas sobre suelos yesíferos normales (Cuadro V).

Son los más extendidos en el sector de la Mancomunidad de Almoguera. Cuando el chucarro y los jabunos apenas se presentan, los gipsófitos genuinos de envergadura más modesta forman un matorral menos evolucionado de herbáceas, tomillos y otros arbustos. Estas formaciones, con menor cobertura, se instalan sobre suelos menos de- 


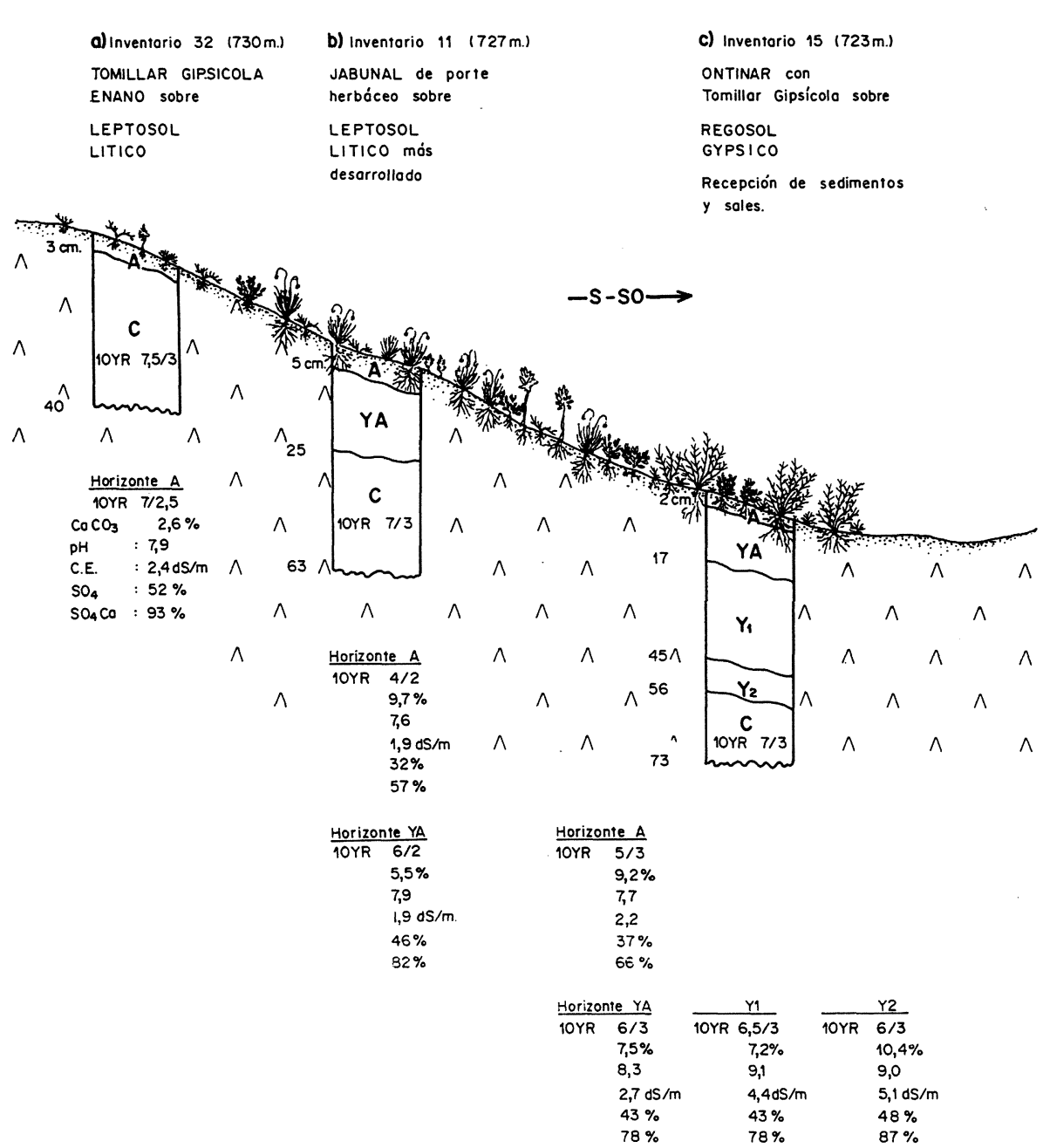

Fig. 1.-Toposecuencia fitoedáfica en sustrato yesífero (Morra de Sagrate. Illana; Guadalajara).

sarrollados (regosoles y leptosoles), minerales, menos estructurados y más proclives a la erosión. La sucesión progresiva no siempre está asegurada, pues si persiste cierta carga antropozoógena, exposiciones soleadas o ventosas, subaridez climática o topográfica, el desarrollo edáfico se ve paralizado o ralentizado y, consecuentemente, la formación queda estabilizada.

Estudios Geográficos, LXII, 244, 2001 
Sin embargo, se observan por otro lado algunas facies que responden a dinámicas progresivas rápidas, cuando están próximas otras formaciones más evolucionadas (romerales, tomillar-salviares, aliagares...), que las circundan, y la acción perturbadora desaparece o se mitiga. Entonces, el tomillo de escamas, el heliantemo conquense o el romerillo actúan como plantas oportunistas e invasoras, restableciendo el avance fitodinámico (inv. 19).

En pocas ocasiones se observa algún gipsófito claramente dominante (inv. 23), sino más bien se establecen diversas codominancias (invs. 19, 20, 21, 22, 24, 25, 26 y 27), en las que prácticamente siempre participa el tomillo de Aranjuez. Otras plantas de alta frecuencia son el tomillo de escamas, el albaque, la Koeleria vallesiana y la Reseda stricta. Se aprecian valores de abundancia-dominancia menores en elementos de matorrales no gipsícolas por comparación con jabunales y chucarrales (invs. 21, 24, 25 y 27), por ser medios aún más exclusivos.

En pocos casos se observan tomillar-herbazales, que son sobre todo de carácter subnitrófilo (invs. 26 y 27), o con efímeros terófitos enanos (invs. 23 y 27). VI).

- Tomillares gipsícolas enanos sobre protosuelos yesíferos (Cuadro

Finalmente, cuando apenas existe suelo, se está formando o es esquelético, la cobertura vegetal de las formaciones gipsícolas se reduce considerablemente $(<15 \%)$, así como el número de especies $(<14)$. Se trata de rodales casi desprovistos de vegetación, de tamaño reducido, muy numerosos, a modo de claros entre el resto de matorrales gipsícolas.

Se instalan unos tomillares de aún más pequeña envergadura, rastreros, postrados y termófilos; situados normalmente en las crestas o resaltes más secos y venteados, en las cimeras de los antecerros yesíferos. En un medio paupérrimo y con líquenes xéricos, esta formación tiene una evidente función pionera y constituye la primera etapa arbustiva en la sucesión.

Está dominada por el Teucrium pumilum (invs. 28 y 30); también están presentes el tomillo de Aranjuez y el albaque, pero con menor abundancia, apareciendo mucho más frecuentemente que antes el pequeño subfrútice que segrega látex, Launaea pumila. Son frecuentes también la Koeleria castellana, la Reseda stricta, la herniaria y el tomillo de escamas, apareciendo apenas el chucarro, los jabunos y el heliantemo 
conquense. La presencia de elementos no gipsícolas es anecdótica (invs. 30 y 33). Salvo el Teucrium, la Koeleria, la herniaria y la Launaea pumila, el vigor y porte de las otras plantas es menor del habitual y apenas pueden competir con éstas (invs. 30 y 31 ).

$\mathrm{El}$ inventario 32 se tomó sobre un leptosol lítico esquelético, como muestra la Figura 1 (a).

\section{Conclusiones florísticas y geoecológicas}

Si en vez de la estructura de la vegetación y la dominancia del elemento florístico principal, se emplea como criterio fundamental estrictamente el de composición florística global (apoyados en la metodología fitosociológica), cabe hacer la siguiente clasificación de los matorrales gipsícolas:

- Matorrales gipsícolas genuinos, por el dominio en las formaciones de gipsófitos exclusivos y, en segundo lugar, subgipsófitos. Responden a los suelos yesíferos normales, yesíferos profundos a subyesíferos y protosuelos yesiferos comentados. Se distinguen:

- Chucarrales (inventario 13).

- Jabunales (inventarios 10, 11 y 12).

- Tomillares gipsícolas (invs. 19, 20, 21, 22 y 23).

- Tomillares gipsícolas enanos (invs. 28, 29, 31 y 32).

- Matorrales ecotónicos de diferente significado geoecológico: sustratos yesíferos o margo-yesíferos mezclados con otros materiales por contactos o asociaciones litológicas (carbonáticos, sílex y detríticos), acúmulo de otras sales, eutrofización del medio, mayor contenido en materia orgánica y transiciones fitodinámicas. Junto a gipsófitos exclusivos -que en algunas localidades pueden llegar a ser secundarios-, aparecen con más frecuencia subgipsófitos y gipsófitos facultativos, así como otros elementos no apetentes de los yesos. Se han detectado las siguientes formaciones:

a) Matorrales ecotónicos donde destacan los elementos gipsícolas genuinos:

Estudios Geográficos, LXII, 244, 2001

$$
-424-
$$


- Chucarral-tomillar común (inv. 6).

- Chucarral-salviar (inv. 7).

- Chucarral-herbazal variado (inv 14).

- Jabunal-juncial morisco (inv. 18).

- Tomillar gipsícola con elementos de salviar (invs. 24 y 25).

- Tomillar gipsícola-romeral (invs. 2 y 3).

- Tomillar gipsícola-salviar (inv. 8).

- Tomillar gipsícola-matorral/herbazal subnitrófilo (inv. 9).

- Tomillar gipsícola-herbazal subnitrófilo (invs. 26 y 27).

- Tomillar gipsícola enano con elementos de romeral (inv. 30).

- Tomillar gipsícola enano-herbazal variado (inv. 33).

b) Matorrales ecotónicos donde los elementos gipsícolas son secundarios:

- Romeral-Chucarral (invs. 1 y 5 ).

- Tomillar mixto (inv. 4).

- Ontinar con tomillos gipsícolas (inv. 15).

- Juncial morisco-jabunal (inv. 16).

- Juncial morisco-tomillar gipsícola (inv. 17).

Como resumen, en la Figura 2 se representa un ejemplo ideal de perfil de vegetación gipsícola y su correspondencia con las unidades geológicas existentes en el área de estudio (véase García-Abad, 1998).

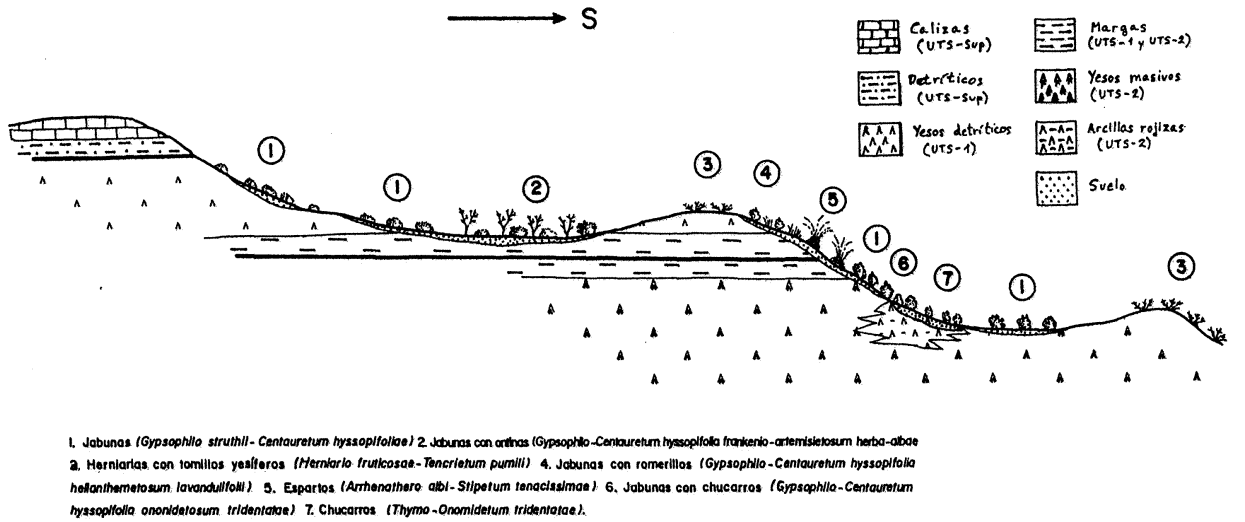

Fig. 2.-Perfil «ideal» de las formaciones gipsícolas en el área de estudio.

Estudios Geográficos, LXII, 244, 2001 
De esta manera, en el área de estudio, las formaciones de vegetación gipsícola genuina no alcanzan superficialmente la mitad del territorio que correspondería geológicamente a facies de dominio yesífero. Gipsófitos facultativos y no gipsófitos entran a formar parte de estas formaciones, cuando junto al sustrato yesífero concurren otros factores físico-naturales y antrópicos que cambian ligeramente las condiciones fitoecológicas más o menos puras y extremas que impone el yeso. Este complejo geoecológico desencadena, pues, una relativa variabilidad florística en la vegetación.

Estudios Geográficos, LXII, 244, 2001 


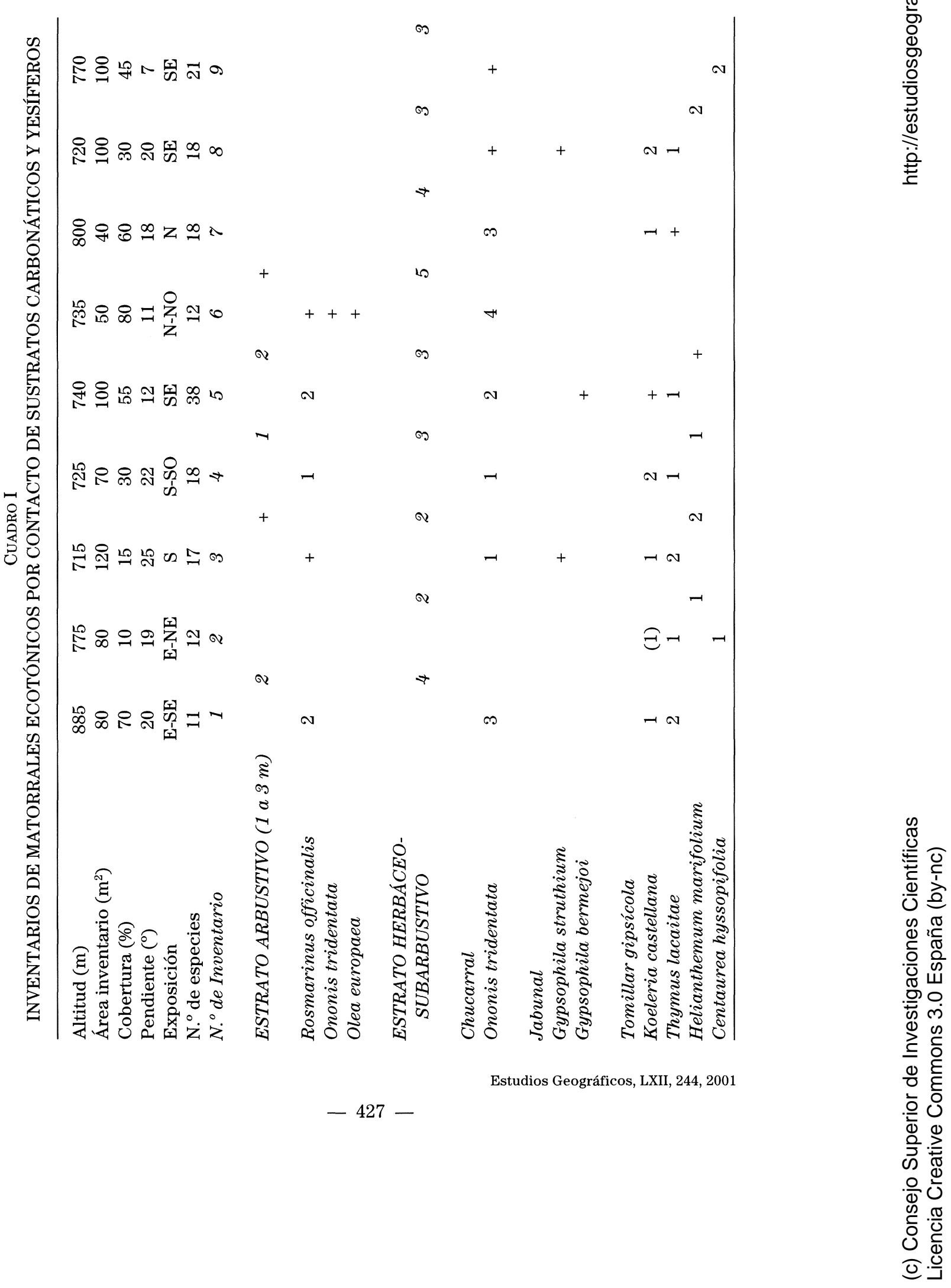




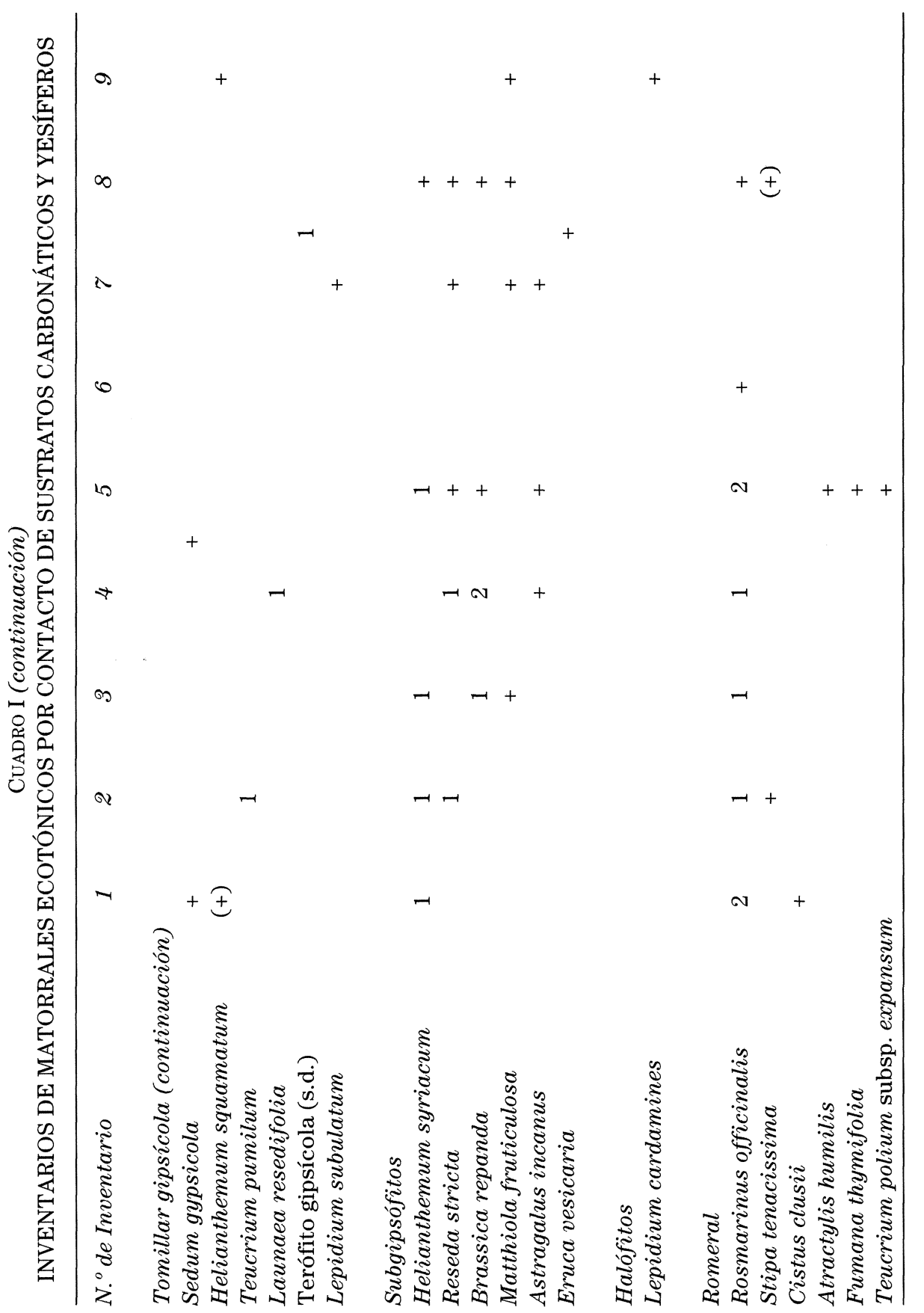

Estudios Geográficos, LXII, 244, 2001 


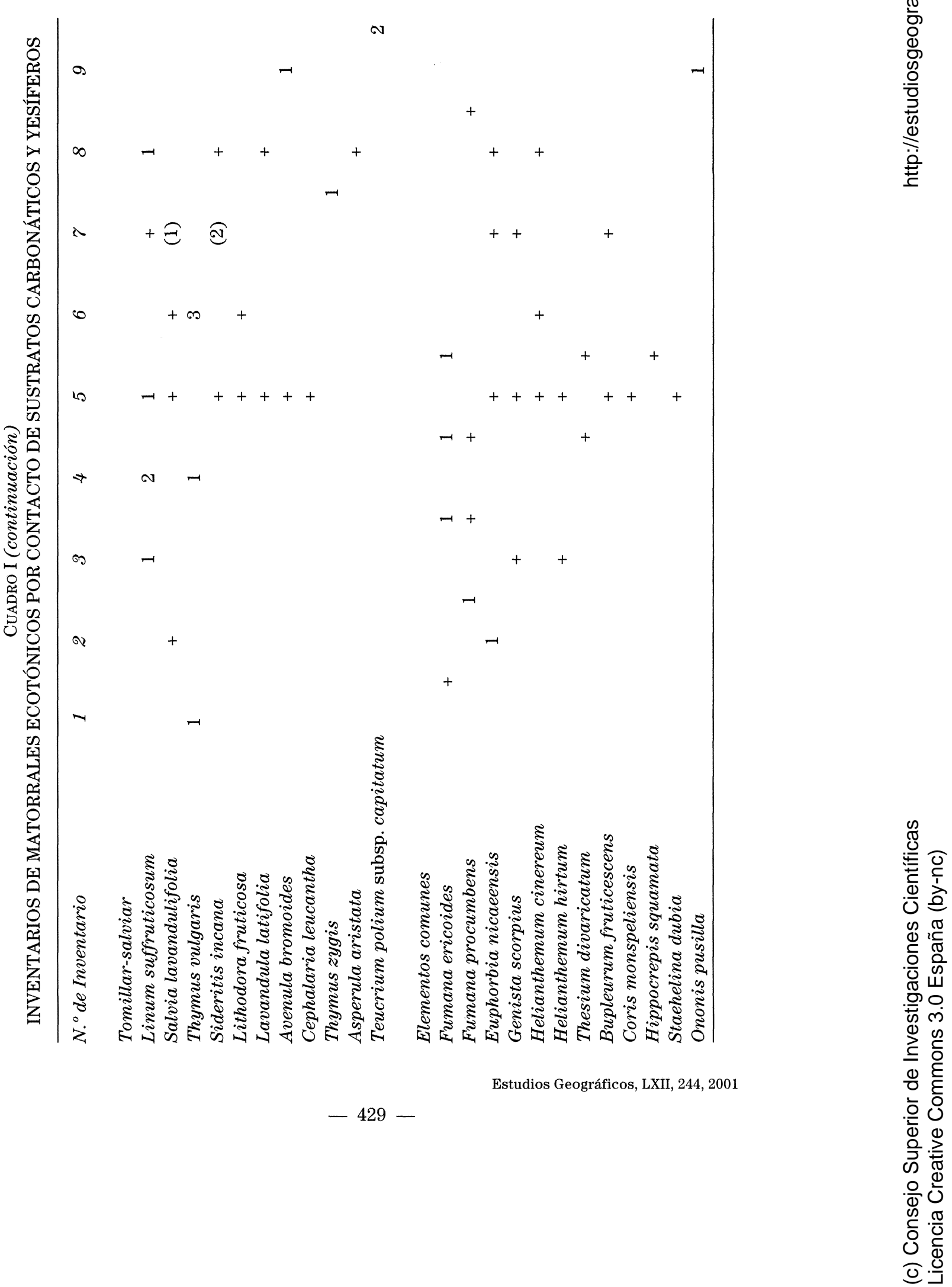




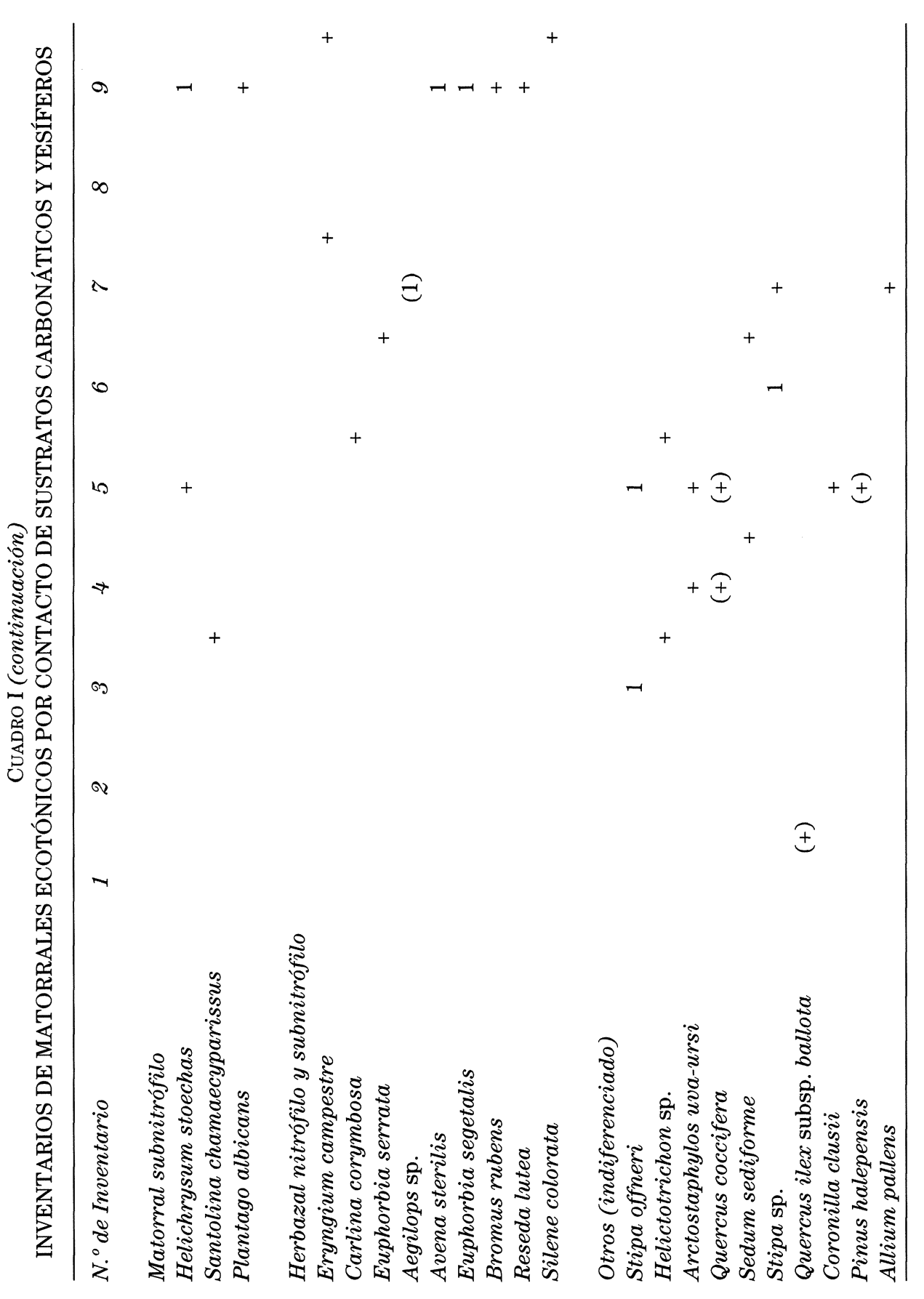

Estudios Geográficos, LXII, 244, 2001 
FITOGEOGRAFÍA DE LA MANCOMUNIDAD DE ALMOGUERA...

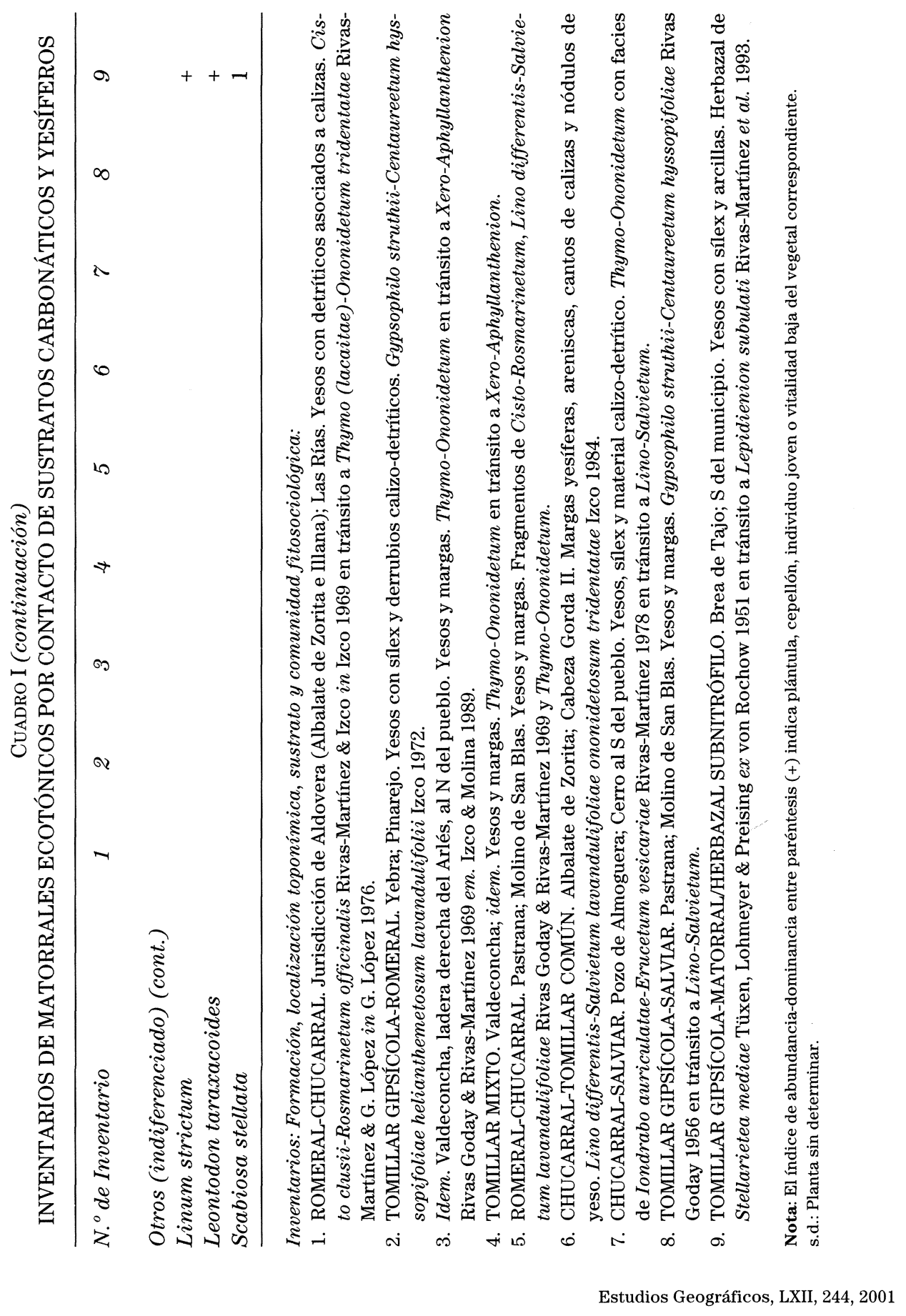

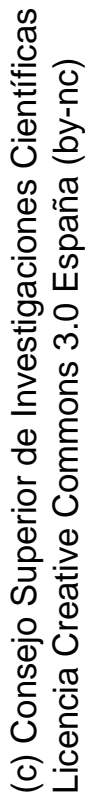


CUADRo II

INVENTARIOS FLORÍSTICOS DE JABUNALES Y CHUCARRALES

\begin{tabular}{|c|c|c|c|c|c|c|c|c|c|c|}
\hline Altitud (m) & 783 & & 727 & & 781 & & 805 & & 745 & \\
\hline Área inventario $\left(\mathrm{m}^{2}\right)$ & 50 & & 36 & & 100 & & 30 & & 100 & \\
\hline Cobertura (\%) & 70 & & 40 & & 75 & & 70 & & 65 & \\
\hline Pendiente $\left({ }^{\circ}\right)$ & 7 & & 9 & & 7 & & 26 & & 20 & \\
\hline Exposición & $\mathrm{S}$ & & S-SE & & S-SE & & $\mathrm{N}$ & & $\mathrm{O}$ & \\
\hline $\mathrm{N}^{\circ}$ de especies & 13 & & 18 & & 23 & & 16 & & 33 & \\
\hline$N^{o}$ de Inventario & 10 & & 11 & & 12 & & 13 & & 14 & \\
\hline \multicolumn{11}{|l|}{ ESTRATO HERBÁCEO- } \\
\hline SUBARBUSTIVO $(<1 \mathrm{~m})$ & & 4 & & 3 & & 5 & & 4 & & 4 \\
\hline \multicolumn{11}{|l|}{ Jabunal } \\
\hline Gypsophila struthium & 4 & & 3 & & 4 & & + & & & \\
\hline Gypsophila bermejoi & & & & & 2 & & & & & \\
\hline \multicolumn{11}{|l|}{ Chucarral } \\
\hline Ononis tridentata & & & & & & & 3 & & 3 & \\
\hline \multicolumn{11}{|l|}{ Tomillar gipsícola } \\
\hline Centaurea hyssopifolia & 1 & & 1 & & 2 & & & & 1 & \\
\hline Thymus lacaitae & & & 2 & & 3 & & 2 & & 2 & \\
\hline Helianthemum squamatum & & & (1) & & 1 & & & & 1 & \\
\hline Lepidium subulatum & & & & + & & + & & & & + \\
\hline Koeleria castellana & & & & & 1 & & 2 & & 1 & \\
\hline Launaea pumila & & & + & & & & 1 & & & \\
\hline Herniaria fruticosa & & & 1 & & & & & & 1 & \\
\hline Launaea resedifolia & & & & & & & & & + & \\
\hline \multicolumn{11}{|l|}{ Subgipsófitos } \\
\hline Reseda stricta & 1 & & 1 & & + & & 2 & & 1 & \\
\hline Matthiola fruticulosa & & & 1 & & + & & 2 & & & \\
\hline Helianthemum syriacum & & & + & & & & & & & \\
\hline Astragalus incanus & & & & & & & 1 & & & \\
\hline Eruca vesicaria & & & & & & & + & & & \\
\hline \multicolumn{11}{|c|}{ Herbazal efímero nanoterofítico } \\
\hline Centaurea melitensis & + & & & & + & & & & & \\
\hline Crupina vulgaris & & & + & & 1 & & & & & \\
\hline Leontodon taraxacoides & & & + & & & & & & 1 & \\
\hline Bombycilaena discolor & & & & & 1 & & & & + & \\
\hline Euphorbia peplus & & + & & & & & & & & \\
\hline Limonium echioides & & + & & & & & & & & \\
\hline
\end{tabular}

Estudios Geográficos, LXII, 244, 2001 
CUADRo II (continuación)

INVENTARIOS FLORÍSTICOS DE JABUNALES Y CHUCARRALES

\begin{tabular}{|c|c|c|c|c|c|c|c|c|}
\hline$N^{o}$ de Inventario & 10 & 11 & 12 & & 13 & & 14 & \\
\hline \multicolumn{9}{|l|}{$\begin{array}{l}\text { Herbazal efímero } \\
\quad \text { nanoterofítico (cont.) }\end{array}$} \\
\hline Linum strictum & & 1 & & & & & & \\
\hline Scabiosa stellata & & 1 & & & & & & \\
\hline Brachypodium distachyon & & & & & & (1) & & \\
\hline Terófito (s.d.) & & & & & 1 & & & \\
\hline Asterolinon linum-stellatum & & & & & & & & 1 \\
\hline Bupleurum semicompositum & & & & & & & & + \\
\hline Crucianella angustifolia & & & & & & & & 1 \\
\hline Euphorbia falcata & & & & & & & 1 & \\
\hline Linaria glauca & & & & & & & 1 & \\
\hline Medicago minima & & & & & & & & 1 \\
\hline Valerianella coronata & & & & & & & & $(+)$ \\
\hline \multicolumn{9}{|l|}{ Elementos del tomillar y romeral } \\
\hline Teucrium polium subsp. capitatum & & 1 & & 1 & & 1 & & \\
\hline Euphorbia nicaeensis & & & 1 & & & & & 1 \\
\hline Hippocrepis comosa & & + & & & & & 1 & \\
\hline Thymus vulgaris & 1 & & & & & & & \\
\hline Salvia lavandulifolia & & & & $(+)$ & & & & \\
\hline Asperula aristata & & & + & & & & & \\
\hline Sideritis incana & & & & & 1 & & & \\
\hline Asphodelus cerasifer & & & & & & & 1 & \\
\hline Stipa tenacissima & & & & & & & 1 & \\
\hline \multicolumn{9}{|l|}{ Matorral nitrófilo y subnitrófilo } \\
\hline Marrubium vulgare & + & & & & & & & \\
\hline Artemisia herba-alba & & & $(+)$ & & & & & \\
\hline Plantago albicans & & & 2 & & & & & \\
\hline Santolina chamaecyparissus & & & & & & + & & \\
\hline \multicolumn{9}{|l|}{ Herbazal nitrófilo, subnitrófilo y otros } \\
\hline Aegilops geniculata & & (1) & & & (2) & & & \\
\hline Bromus rubens & & & 1 & & & & 1 & \\
\hline Anchusa sp. & + & & & & & & & \\
\hline Euphorbia serrata & + & & & & & & & \\
\hline Bromus madritensis & & 1 & & & & & & \\
\hline Filago lutescens & & 1 & & & & & & \\
\hline Avena sp. & & & 1 & & & & & \\
\hline Eryngium campestre & & & 1 & & & & & \\
\hline
\end{tabular}


CUADRO II (continuación)
INVENTARIOS FLORÍSTICOS DE JABUNALES Y CHUCARRALES

\begin{tabular}{|c|c|c|c|c|c|}
\hline$N^{o}$ de Inventario & 10 & 11 & 12 & 13 & 14 \\
\hline \multicolumn{6}{|c|}{$\begin{array}{l}\text { Herbazal nitrófilo, subnitrófilo } \\
\text { y otros (continuación) }\end{array}$} \\
\hline Euphorbia segetalis & & & 1 & & \\
\hline Allium pallens & & & & 1 & \\
\hline Aegilops triuncialis & & & & & 1 \\
\hline Alyssum serpyllifolium & & & & & $(+)$ \\
\hline Erodium cicutarium & & & & & + \\
\hline Filago spathulata & & & & & 1 \\
\hline Medicago rigidula & & & & & + \\
\hline Melilotus sp. & & & & & 1 \\
\hline Sanguisorba minor & & & & & 1 \\
\hline Taraxacum sp. & & & & & 1 \\
\hline Thapsia villosa & & & & & (1) \\
\hline Tragopogon porrifolius & & & & & + \\
\hline
\end{tabular}

Inventarios: Formación, localización toponímica, sustrato y comunidad fitosociológica:

10. JABUNAL. Albares; Dehesa de la Flora. Yesos (gypsisol háplico). Facies fragmentaria de Gypsophilo struthii-Centaureetum hyssopifoliae Rivas Goday 1956.

11. JABUNAL. Illana; Morra de Sagrete. Yesos (Leptosol lítico). Gypsophilo-Centaureetum con facies de Iondrabo auriculatae-Erucetum vesicariae Rivas-Martínez 1978.

12. JABUNAL. Illana; Corral de Tomico. Yesos con algunos pequeños cantos de sílex. Gypsophilo-Centaureetum con facies de Iondrabo-Erucetum.

13. CHUCARRAL. Pozo de Almoguera; Cerro al S del pueblo. Yesos. Thymo (lacaitae)-Ononidetum tridentatae Rivas-Martínez \& G. López in G. López 1976 con facies de Iondrabo-Erucetum.

14. CHUCARRAL-HERBAZAL VARIADO. Driebes. Al E-SE, cerca del pueblo. Yesos tableados y material detrítico yesífero. Thymo-Ononidetum enriquecido con herbazales de Trachynietalia distachyae Rivas-Martínez 1978 y de Brometalia rubenti-tectorum (Rivas Goday \& Rivas-Martínez 1963) Rivas-Martínez \& Izco 1977. 


\section{CUADRO III \\ DETERMINACIÓN Y ANÁLISIS DEL SUELO EN PARCELA \\ DEL INVENTARIO 10}

Tipo de Suelo (FAO): GYPSISOL HÁPLICO. En todos los horizontes: estructura sin grado, ligeramente adherente en mojado, de consistencia suelta en seco y ligeramente plástico.

\begin{tabular}{|c|c|c|c|c|c|c|}
\hline $\begin{array}{c}\text { Horizonte } \\
\text { cm }\end{array}$ & $\begin{array}{c}\text { Color } \\
\text { mojado }\end{array}$ & $\begin{array}{c}\% \mathrm{CaCO}_{3} \\
\text { equivalente }\end{array}$ & $\begin{array}{c}\text { pH } \mathrm{H}_{2} \mathrm{O} \\
1: 2.5\end{array}$ & $\begin{array}{c}\text { C.E. } \\
\text { dS } \cdot \mathbf{m}^{-1}\end{array}$ & $\begin{array}{c}\% \mathrm{SO}_{4}= \\
\text { equivalente }\end{array}$ & $\begin{array}{c}\% \\
\mathrm{SO}_{4} \mathrm{Ca}\end{array}$ \\
\hline $\begin{array}{c}\mathrm{A} \\
0-3 \mathrm{~cm}\end{array}$ & $\begin{array}{l}10 \mathrm{YR} \\
5 / 3\end{array}$ & 17.4 & 7.5 & 2.0 & 27.0 & 48.0 \\
\hline $\begin{array}{c}\text { AY } \\
3-18\end{array}$ & $\begin{array}{l}10 \mathrm{YR} \\
5.5 / 3\end{array}$ & 13.5 & 7.7 & 1.9 & 53.0 & 95.0 \\
\hline $\begin{array}{c}\mathrm{Y} \\
18-50\end{array}$ & $\begin{array}{l}10 \mathrm{YR} \\
7 / 2\end{array}$ & 3.5 & 7.8 & 1.8 & 50.0 & 90.0 \\
\hline
\end{tabular}

C.E.: Conductividad Eléctrica a $25^{\circ} \mathrm{C}$, proporción 1:2,5. dS: decisiemen.

Técnicas de análisis según GUITIÁN, F. y CARBALLÁS, M.T. (1976) y PORTA, J. et al. (1986). Nomenclatura de horizontes según PORTA, J. et al. (1994). 


\section{CUADRo IV \\ INVENTARIOS DE MATORRALES GIPSÍCOLAS ENRIQUECIDOS CON ONTINAR Y JUNCIAL}

Altitud (m)

Área inventario $\left(\mathrm{m}^{2}\right)$

Cobertura (\%)

Pendiente $\left({ }^{\circ}\right)$

Exposición

$\mathrm{N} .^{\circ}$ de especies

$N .^{\circ}$ de Inventario

ESTRATO HERBÁCEO-

SUBARBUSTIVO

Jabunal

Gypsophila bermejoi

Otros Gipsófitos genuinos

Helianthemum squamatum

Launaea resedifolia

Herniaria fruticosa

Arenaria cavanillesiana

Koeleria castellana

Lepidium subulatum

Sedum gypsicola

Thymus lacaitae

Centaurea hyssopifolia

Subgipsófitos

Reseda stricta

Eruca vesicaria

Helianthemum syriacum

Matthiola fruticulosa

\section{Halófitos}

Lepidium cardamines

Elementos del ontinar

Artemisia herba-alba

Elementos del juncial

Schoenus nigricans

Elymus curvifolius

Plantago maritima

$\begin{array}{cccc}723 & 670 & 783 & 670 \\ 18 & 20 & 20 & 60 \\ 55 & 85 & 30 & 60 \\ 7 & 8 & 8 & 14 \\ \text { S-SO } & \text { SE } & \text { S-SO } & \text { SE } \\ 11 & 12 & 18 & 21 \\ 15 & 16 & 17 & 18\end{array}$

\section{4}

5

3

4

4

4

(1)

$(+)$

1

2

1

(+)

1

1

1

$\begin{array}{ccc}+ & 1 & 1 \\ + & & 1 \\ & + & \\ & 1 & \end{array}$

1

Estudios Geográficos, LXII, 244, 2001 


\section{CUADRO IV (continuación) \\ INVENTARIOS DE MATORRALES GIPSÍCOLAS ENRIQUECIDOS CON ONTINAR Y JUNCIAL}

\begin{tabular}{|c|c|c|c|c|c|c|c|c|}
\hline$N .^{\circ}$ de Inventario & 15 & & 16 & & 17 & & 18 & \\
\hline \multicolumn{9}{|l|}{ Herbazal subnitrófilo } \\
\hline Bromus tectorum & & & + & & & & 1 & \\
\hline Centaurea melitensis & & & 1 & & & & 1 & \\
\hline Lactuca serriola & & & 2 & & & & + & \\
\hline Tragopogon porrifolius & & & + & & & & + & \\
\hline Plantago albicans & & & & & + & & + & \\
\hline Aegilops geniculata & 1 & & & & & & & \\
\hline Filago lutescens & 1 & & & & & & & \\
\hline Aegilops triuncialis & & & & & (1) & & & \\
\hline Avena sterilis & & & & & & & + & \\
\hline Sonchus asper & & & & & & & & + \\
\hline \multicolumn{9}{|l|}{ Otros (indiferenciado) } \\
\hline Linum strictum & & & + & & & & 1 & \\
\hline Crucianella angustifolia & & + & & & & & & \\
\hline Euphorbia nicaeensis & & + & & & & & & \\
\hline Hippocrepis comosa & + & & & & & & & \\
\hline Gramínea (s.d.) & 1 & & & & & & & \\
\hline Dactylis glomerata & & & & + & & & & \\
\hline Bombycilaena discolor & & & & & & 1 & & \\
\hline Crupina vulgaris & & & & & & & 1 & \\
\hline Stipa barbata & & & & & + & & & \\
\hline Stipa offneri & & & & & + & & & \\
\hline Allium sphaerocephalon & & & & & & & & 1 \\
\hline Convolvulus lineatus & & & & & & & & + \\
\hline Scabiosa stellata & & & & & & & + & \\
\hline Thapsia villosa & & & & & & & & + \\
\hline
\end{tabular}

Inventarios: Formación, localización toponímica, sustrato y comunidad fitosociológica:

15. ONTINAR con tomillos gipsícolas. Illana; Morra de Sagrete. Yesos y material detrítico (Regosol gypsico). Fragmento de Lepidienion subulati Rivas-Martínez et al. 1993 con facies de Artemisia herba-albae - Frankenietum thymifoliae RivasMartínez \& Izco in Izco 1972.

16. JUNCIAL MORISCO-JABUNAL. Yebra; El Portillo. Yesos y margas yesíferas. Schoeno nigricantis-Plantaginetum maritimae Rivas-Martínez 1984 con facies de Gypsophilo struthii-Centaureetum hyssopifoliae Rivas Goday 1956.

17. JUNCIAL MORISCO-TOMILLAR GIPSÍCOLA. Illana; Corral de Tomico. Yesos. Gypsophilo-Centaureetum con facies de Schoeno-Plantaginetum.

18. JABUNAL-JUNCIAL MORISCO. Yebra; El Portillo. Yesos y margas yesíferas. Schoeno-Plantaginetum con facies de Gypsophilo-Centaureetum.

Estudios Geográficos, LXII, 244, 2001 


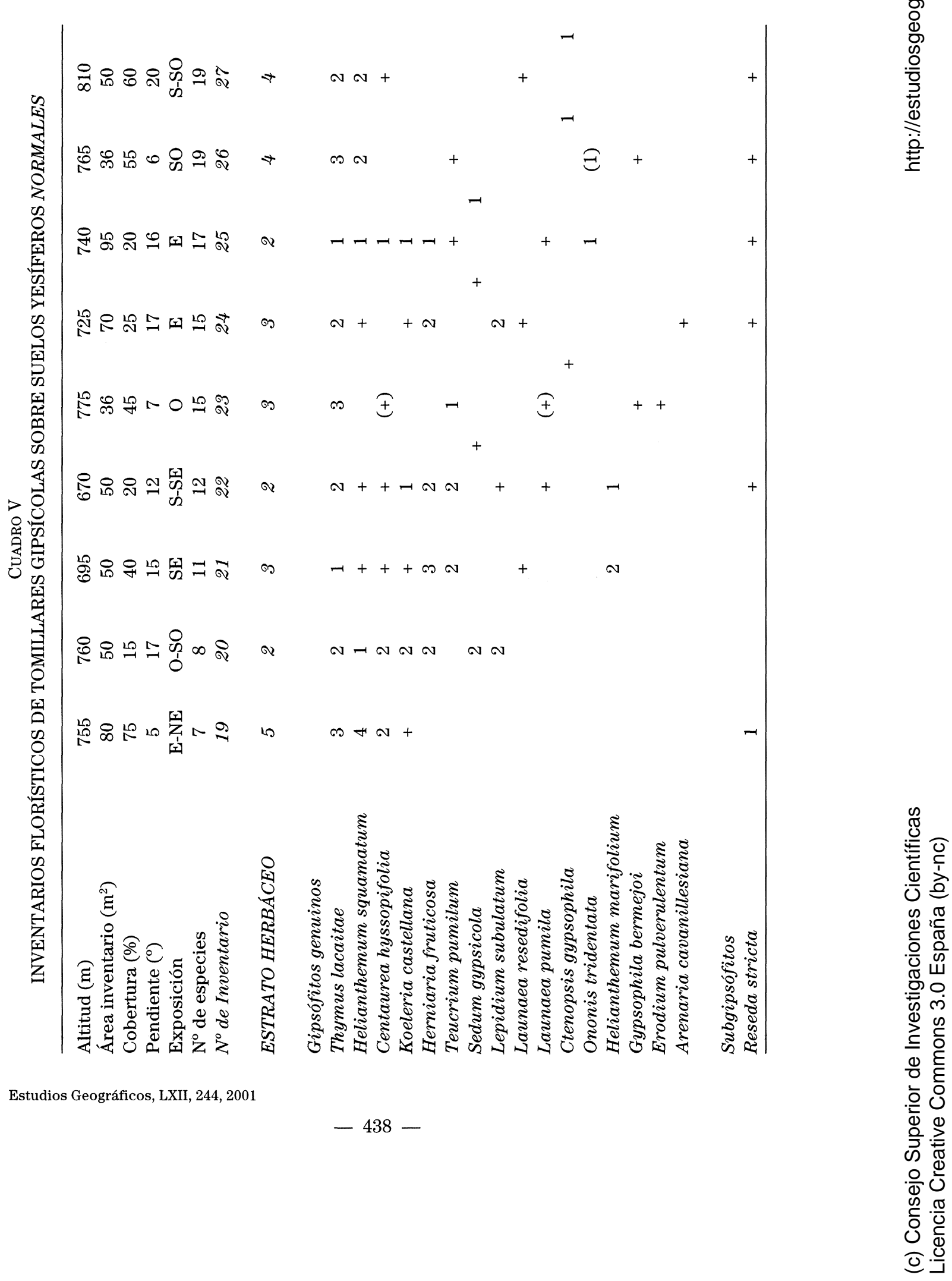




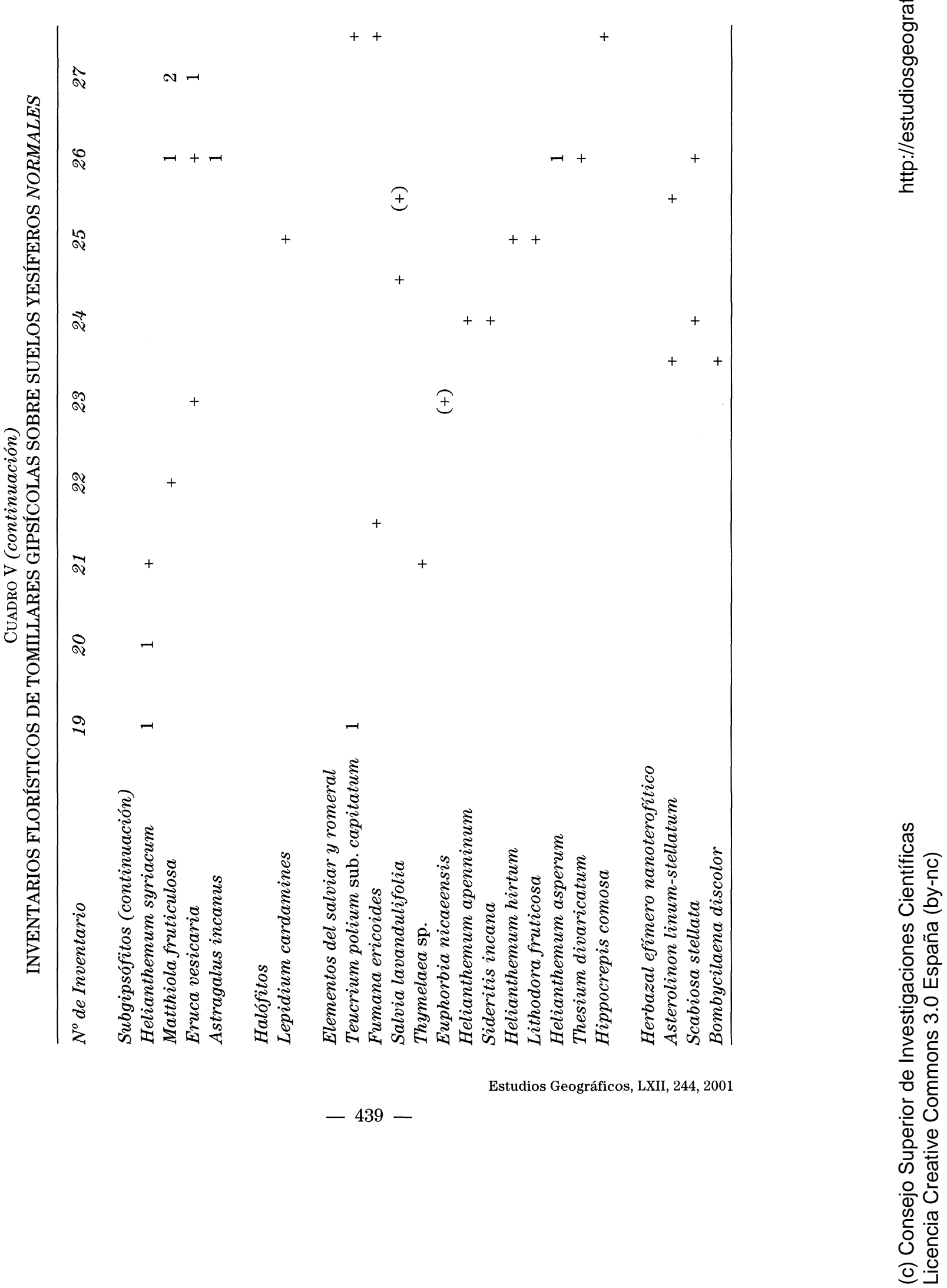




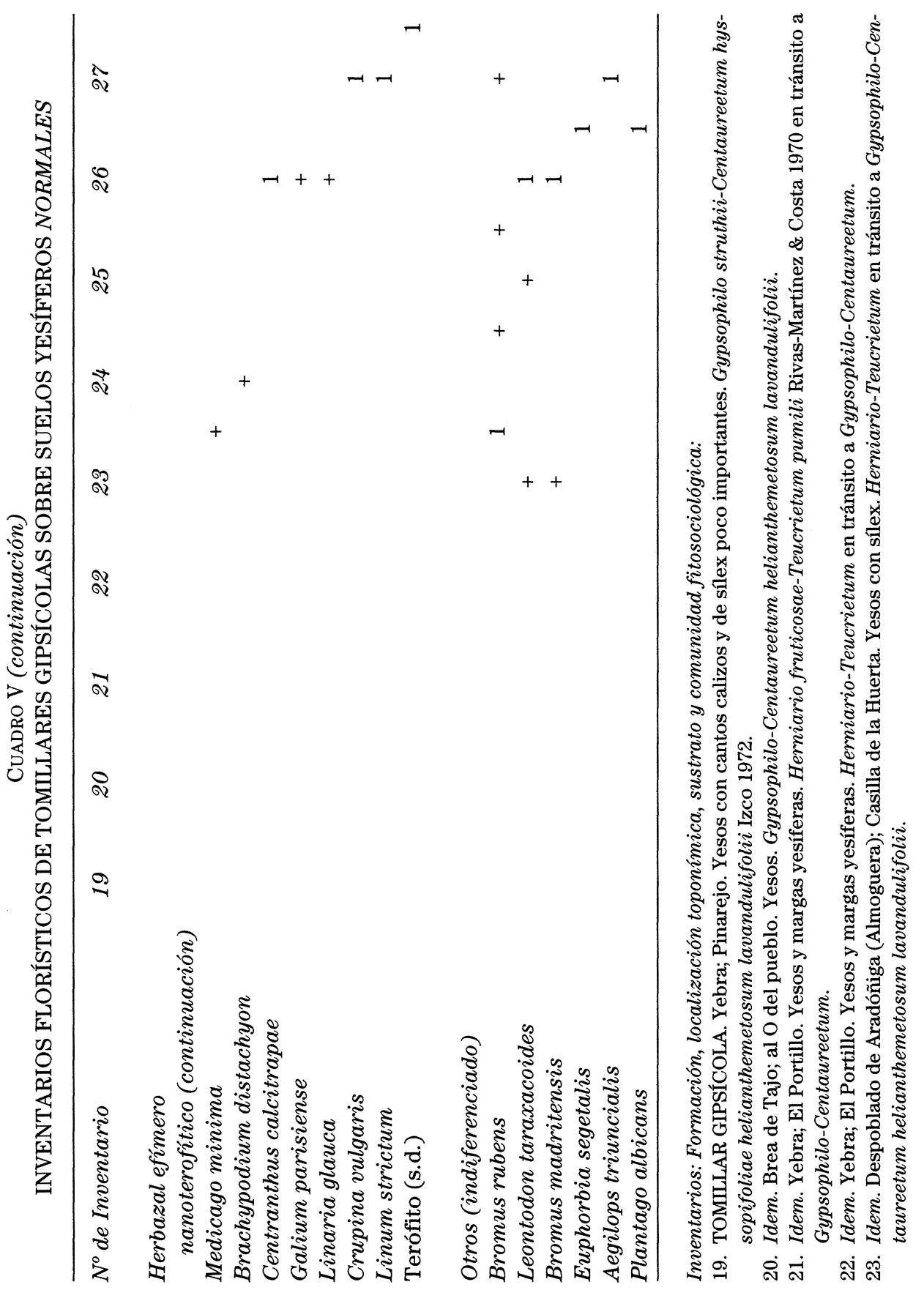




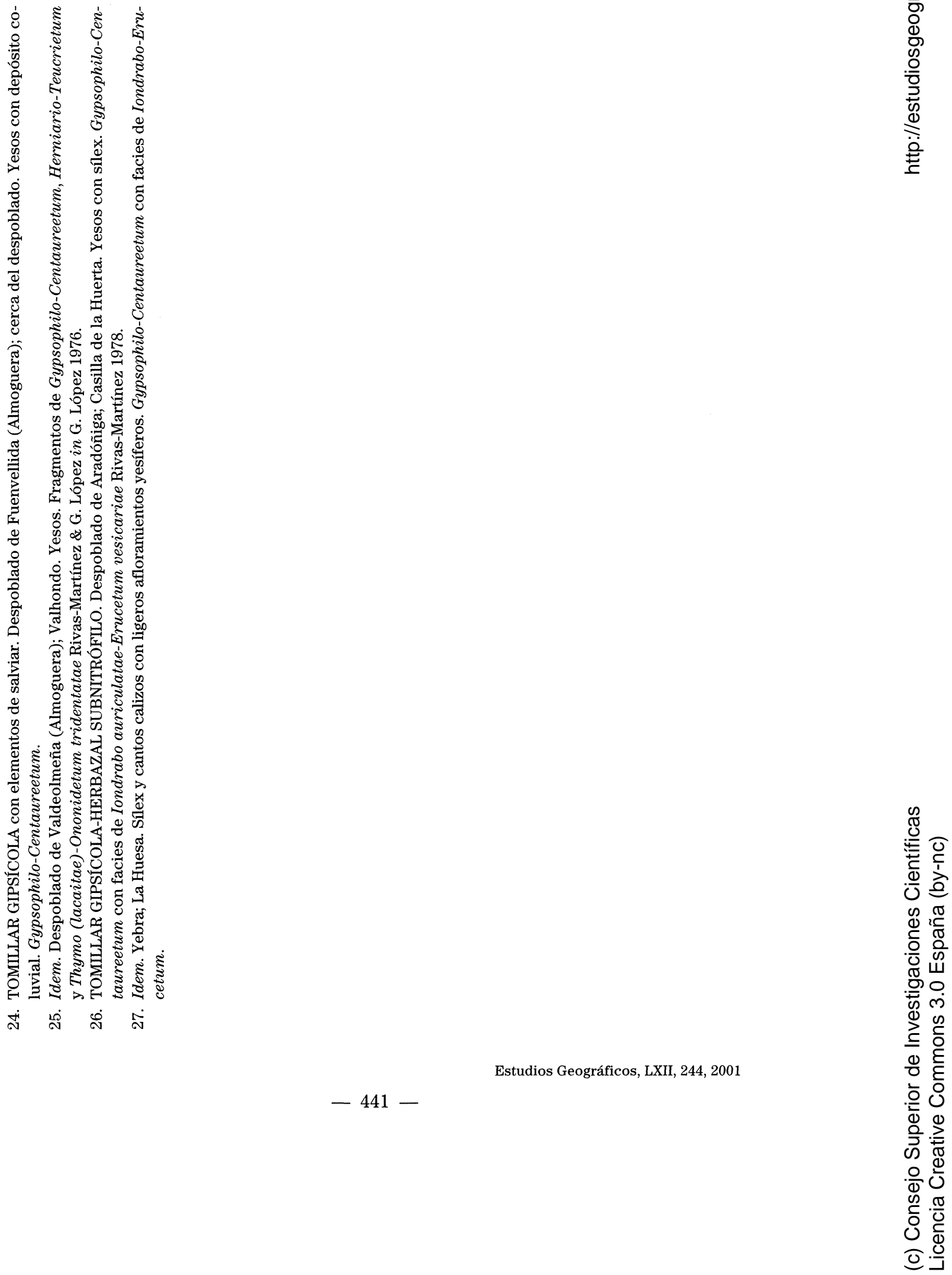


CuAdRo VI

INVENTARIOS FLORÍSTICOS DE TOMILLARES GIPSÍCOLAS ENANOS SOBRE PROTOSUELOS YESIFEROS

\begin{tabular}{|c|c|c|c|c|c|c|}
\hline Altitud (m) & 760 & 790 & 740 & 785 & 730 & 760 \\
\hline Área inventario $\left(\mathrm{m}^{2}\right)$ & 10 & 20 & 40 & 30 & 16 & 80 \\
\hline Cobertura (\%) & 8 & 5 & 15 & 5 & 5 & 10 \\
\hline Pendiente $\left({ }^{\circ}\right)$ & 17 & 20 & 12 & 17 & 9 & 12 \\
\hline Exposición & $\mathrm{O}-\mathrm{SO}$ & $\mathrm{SE}$ & $\mathrm{E}$ & $\mathrm{S}-\mathrm{SO}$ & $\mathrm{S}-\mathrm{SO}$ & $\mathrm{O}$ \\
\hline $\mathrm{N}^{\circ}$ de especies & 8 & 9 & 13 & 13 & 13 & 20 \\
\hline$N^{o}$ de Inventario & 28 & 29 & 30 & 31 & 32 & 33 \\
\hline ESTRATO HERBÁCEO $(<0.5 \mathrm{~m})$ & 2 & 2 & 2 & 2 & 2 & 2 \\
\hline \multicolumn{7}{|l|}{ Gipsófitos genuinos } \\
\hline Teucrium pumilum & 2 & 1 & 2 & (1) & 1 & 1 \\
\hline Koeleria castellana & 1 & 2 & 1 & 1 & 1 & 1 \\
\hline Thymus lacaitae & 1 & 1 & 1 & (1) & 1 & 1 \\
\hline Centaurea hyssopifolia & 1 & 1 & + & $(+)$ & 1 & 1 \\
\hline Launaea pumila & + & + & + & $(+)$ & + & + \\
\hline Herniaria fruticosa & 1 & 1 & & (1) & 1 & \\
\hline Helianthemum squamatum & & + & (1) & & (1) & 1 \\
\hline Sedum gypsicola & & & & 1 & 1 & (1) \\
\hline Lepidium subulatum & & & & $(+)$ & 1 & 1 \\
\hline Helianthemum marifolium & & & $(+)$ & 1 & & \\
\hline Ononis tridentata & & + & & & & \\
\hline Launaea resedifolia & & + & & & & \\
\hline Arenaria cavanillesiana & & & & + & & \\
\hline \multicolumn{7}{|l|}{ Subgipsófitos } \\
\hline Reseda stricta & + & & 1 & (1) & 1 & + \\
\hline Helianthemum syriacum & & & (1) & + & & \\
\hline Eruca vesicaria & & & & & & + \\
\hline \multicolumn{7}{|l|}{ Halófitos } \\
\hline Schoenus nigricans & & + & & & & \\
\hline Lepidium cardamines & & & + & & & \\
\hline \multicolumn{7}{|l|}{ Elementos del romeral } \\
\hline Fumana ericoides & & & & $(+)$ & + & \\
\hline Rosmarinus officinalis & & & $(+)$ & & & \\
\hline Stipa tenacissima & & & $(+)$ & & & \\
\hline Asphodelus cesarifer & & & & & & (1) \\
\hline Helianthemum apenninum & & & & & & 1 \\
\hline
\end{tabular}

Estudios Geográficos, LXII, 244, 2001 


\section{CUADRO VI (continuación)}

INVENTARIOS FLORÍSTICOS DE TOMILLARES GIPSÍCOLAS ENANOS SOBRE PROTOSUELOS YESIFEROS

\begin{tabular}{|c|c|c|c|c|c|c|}
\hline$N^{o}$ de Inventario & 28 & 29 & 30 & 31 & 32 & 33 \\
\hline \multicolumn{7}{|l|}{ Otros (indiferenciado) } \\
\hline Bromus madritensis & & & & & & \\
\hline Filago lutescens & & & & & 1 & \\
\hline Scabiosa stellata & & & & & 1 & \\
\hline Bombycilaena discolor & & & & & & 1 \\
\hline Bromus rubens & & & & & & 1 \\
\hline Crupina vulgaris & & & & & & \\
\hline Erodium cicutarium & & & & & & + \\
\hline Leontodon taraxacoides & & & & & & + \\
\hline Linaria glauca & & & & & & 1 \\
\hline Sanguisorba minor & & & & & & 1 \\
\hline
\end{tabular}

Inventarios: Formación, localización toponímica, sustrato y comunidad fitosociológica:

28. TOMILLAR GIPSÍCOLA ENANO. Brea de Tajo; al O cerca del pueblo. Yesos. Herniario fruticosae-Teucrietum pumili Rivas-Martínez \& Costa 1970.

29. Idem. Brea de Tajo; Corral del Quiñonero. Yesos. Herniario-Teucrietum.

30. TOMILLAR GIPSÍCOLA ENANO con elementos de romeral. Yebra; Pinarejo. Yesos. Herniario-Teucrietum.

31. TOMILLAR GIPSÍCOLA ENANO. Illana; Corral de Tomico. Yesos. Herniario-Teucrietum.

32. Idem. Illana; Morra de Sagrete. Yesos (Leptosol lítico). Herniario-Teucrietum en tránsito a Gypsophilo struthii-Centaureetum hyssopifoliae Rivas Goday 1956.

33. TOMILLAR GIPSÍCOLA ENANO-HERBAZAL VARIADO. Driebes; al E-SE cerca del pueblo. Yesos. Herniario-Teucrietum en tránsito a Gypsophilo-Centaureetum ligeramente enriquecido con facies de Iondrabo auriculatae-Erucetum vesicariae Rivas-Martínez 1978. 


\section{BIBLIOGRAFÍA}

BiRkELAND, P. W. (1984): Soils and Geomorphology. New York. Oxford University Press. $367 \mathrm{p}$.

Costa TAlens, M. (1974): «Estudio fitosociológico de los matorrales de la provincia de Madrid» en Anales del Instituto Botánico A. J. Cavanilles, 31 (1). Madrid, pp. 225315.

GARCÍA-ABAD Alonso, J. J. (1996a): «Vegetation and soils on gypsiferous outcrops: Geographical contribution in an Eastern Sector of Madrid Basin (Spain)» in PocH, R. M (Ed.): Proceedings of the International Symposium on Soils with Gypsum. Lleida, p. 58.

- (1996b): «Evapotranspiración y balances hídricos en un área de transición climática de la cuenca del Tajo. Aportación a la cartografía geoecológica para su planificación ambiental» en Marzol, M. V.; DorTa, P.; Valladares, P. (Eds.): Clima y agua: la gestión de un recurso climático. La Laguna, pp. 199-209.

- (1998): «Fitogeografía de la Mancomunidad de Almoguera. Formaciones leñosas climatófilas no gipsícolas» en Estudios Geográficos, 230. Madrid, pp. 35-60.

GarRido MEgías, A.; ORDóñez, S. y CALVo SorAndo, J. P. (1983): «Nuevas aportaciones al conocimiento geológico de la Cuenca de Madrid» en Revista de Materiales y Procesos Geológicos, 1. Madrid, pp. 163-191.

GÉHU, J. M. \& RivaS-MARTínez, S. (1981): «Notions fondamentales de Phytosociologie» en Berichte der Internationalen Symposien der Internationalen Vereinigung für Vegetationskunde. (Rinteln, 1980). Vaduz, pp. 5-33.

Guitián OJea, F. y CARBAllás Fernández, M. T. (1976): Técnicas de análisis de suelos. Santiago de Compostela. Pico Sacro. 288 p.

Hernando, V.; SÁnchez Conde, M. P. y Contreras, J. G. (1963): «Influencia de los niveles de yeso y de humedad en la fertilidad de un suelo yesoso» en Anales de Edafología y Agrobiología, 22. Madrid, pp. 323-337.

Izco, J. (1972): «Coscojales, Romerales y Tomillares de la provincia de Madrid» en Anales del Instituto Botánico A. J. Cavanilles, 29. Madrid, pp. 70-108.

- (1984): Madrid Verde. Madrid. Ministerio de Agricultura, Pesca y Alimentación y Comunidad de Madrid. $517 \mathrm{p}$.

Jimeno MaRTín, L. y GonzÁlez Ponce, R. (Dirs.) (1987): La fertilidad de los suelos de mayor interés agrícola de la provincia de Guadalajara. Madrid. CSIC y Junta de Comunidades de Castilla-La Mancha. $290 \mathrm{p}$.

MontURiol, F. y AlCALÁ DEL Olmo, L. (1990): Mapa de asociaciones de suelos de la Comunidad de Madrid. Escala 1:100.000. Madrid. Comunidad Autónoma de Madrid. CSIC. 71 p. + 1 mapa.

Peinado Lorca, M. y Martínez Parras, J. M. (1985): El paisaje vegetal de Castilla-La Mancha. Toledo. Junta de Comunidades de Castilla-La Mancha. $230 \mathrm{p}$.

PoRTA, J.; LóPez-ACEvedo, M. y RodRÍGUez, R. (1986): Técnicas y experimentos en Edafología. Barcelona. Col.legi Oficial d'Enginyers Agrònoms de Catalunya. $283 \mathrm{p}$.

PoRTA, J.; LÓPEZ-ACEVEDO, M y RoQUERo, C. (1994): Edafología. Para la agricultura y el medio ambiente. Madrid. Mundi-Prensa. $807 \mathrm{pp}$.

Rivas-Martínez, S. y Costa TALENS, M. (1970): «Comunidades gipsícolas del centro de España» en Anales del Instituto Botánico A. J. Cavanilles, 27. Madrid, pp. 193-224.

Rivas-Martínez, S.; Asensi, A.; Costa, M.; Fernández-GonzÁlez, F.; Llorens, L.; Masalles, R.; Molero Mesa, J.; Penas, A. y Pérez de Paz, P. L. (1993): «El Proyecto de Cartografía e inventariación de los tipos de hábitats de la Directiva 92/43/CEE en España» en Colloques Phytosociologiques, 22. Bailleul, pp. 611-661. 
RESUMEN: Fitogeografía de la Mancomunidad de Almoguera (II). Estudio especial de las formaciones de matorrales gipsícolas. Este trabajo continúa un estudio anterior de carácter fitogeográfico. A partir de un enfoque convergente entre los métodos geográfico y fitosociológico para el estudio de la vegetación, se determinan las formaciones de matorrales gipsícolas de un sector de la Baja Alcarria (Mancomunidad de Almoguera): chucarrales, jabunales, tomillares gipsícolas y matorrales ecotónicos.

PALABRAS CLAVE: Fitogeografía. Matorrales gipsícolas. La Alcarria. Mancomunidad de Almoguera.

ABSTRACT: Phytogeography of the Pasturage Community of Almoguera (II). Special Study on gypsicolous scrub vegetation. This study continues an other previous on the Phytogeography of a Southern Alcarria Sector (Pasturage Community of Almoguera). It determines the scrub on gypsiferous soils by means of a convergent approach between the geographical and phytosociological methods to vegetation survey: scrub of Ononis tridentata, scrub of Gypsophila sp., gypsicolous tomillares and mixed scrub.

KEY wORDs: Phytogeography. Gypsicolous scrub. La Alcarria. Pasturage Community of Almoguera.

RÉSumÉ: Phytogéographie de la Communauté de pâturages d'Almoguera (II). Étude spécial des formations de matorrales sur gypses. Ce travail poursuit un autre antérieur sur la Phytogéographie d'un secteur de la Basse Alcarrie (Communauté de pâturages d'Almoguera). A partir d'une demarche convergente entre les méthodes géographique et phytosicologique pour l'étude de la végétation, on a déterminé formations sur gypses: $m a$ torrales d'Ononis tridentata, matorrales d'Gypsophila sp., tomillares gypseuses et matorrales de transition.

Mots CLÉs: Phytogéographie. Matorrales sur gypses. La Alcarria. Communauté de pâturages d'Almoguera.

Agradecimientos. Deseo expresar mi agradecimiento a los Dres. M. De la Cruz y A. Escudero (Departamento de Biología Vegetal. Universidad Politécnica de Madrid), al Dr. D. Sánchez-Mata y Dra. P. Cantó (Dpto. de Biología Vegetal II. Universidad Complutense de Madrid), y a la Dra. A. M. Moreno García (Dpto. de Edafología. Universidad Complutense) por su consejo, ayuda y compañía en trabajos de campo. Igualmente quiero agradecer al Departamento de Edafología de la Universidad Complutense de Madrid el haber puesto a mi disposición su laboratorio para el análisis y determinación de suelos. 